\title{
Intraoperative hypotension is associated with increased postoperative complications in patients undergoing surgery for pheochromocytoma-paraganglioma: a retrospective cohort study
}

\author{
Nan $\mathrm{Li}^{1 \dagger}$, Hao Kong ${ }^{1 \dagger}$, Shuang-Ling $\mathrm{Li}^{1}$, Sai-Nan Zhu' ${ }^{2}$, Zheng Zhang ${ }^{3}$ and Dong-Xin Wang ${ }^{1 *}$ (D)
}

\begin{abstract}
Background: Dramatic hemodynamic fluctuation occurs frequently during surgery for pheochromocytoma or paraganglioma. However, the criteria of intraoperative hemodynamic instability vary widely, and most of them were defined arbitrarily but not according to patients' prognosis. The objective was to analyze the relationship between different thresholds and durations of intraoperative hyper-/hypotension and the risk of postoperative complications in patients undergoing surgery for pheochromocytoma or paraganglioma.

Methods: This was a retrospective single-center cohort study performed in a tertiary care hospital from January 1 , 2005 to December 31, 2017. Three hundred twenty-seven patients who underwent surgery for pheochromocytoma or paraganglioma, of which the diagnoses were confirmed by postoperative pathologic examination, were enrolled. Those who were less than 18 years, underwent surgery involving non-tumor organs, or had incomplete data were excluded. The primary endpoint was a composite of the occurrence of AKI or other complications during hospital stay after surgery. Multivariate Logistic regression models were used to analyze the association between different thresholds and durations of intraoperative hyper-/hypotension and the development of postoperative complications.
\end{abstract}

Results: Forty three (13.1\%) patients developed complications during hospital stay after surgery. After adjusting for confounding factors, intraoperative hypotension, defined as systolic blood pressure (SBP) of $\leq 95 \mathrm{mmHg}$ for $\geq 20 \mathrm{~min}$ (OR 3.211; $99 \% \mathrm{Cl} 1.081-9.536 ; P=0.006)$, SBP of $\leq 90 \mathrm{mmHg}$ for $\geq 20 \mathrm{~min}(\mathrm{OR} 3.680 ; 98.8 \% \mathrm{Cl} 1.107-12.240 ; P=$ 0.006), SBP of $\leq 85 \mathrm{mmHg}$ for $\geq 10 \mathrm{~min}(\mathrm{OR} 3.975 ; 98.3 \% \mathrm{Cl} 1.321-11.961 ; P=0.003)$, and $\mathrm{SBP}$ of $\leq 80 \mathrm{mmHg}$ for $\geq 1$ $\min (\mathrm{OR} 3.465 ; 95 \% \mathrm{Cl} 1.484-8.093 ; P=0.004)$, were associated with an increased risk of postoperative complications. On the other hand, intraoperative hypertension was not significantly associated with the development of postoperative complications.

(Continued on next page)

\footnotetext{
* Correspondence: wangdongxin@hotmail.com; dxwang65@bjmu.edu.cn

${ }^{+} \mathrm{Nan} \mathrm{Li}$ and Hao Kong contributed equally to this work.

'Department of Anesthesiology and Critical Care Medicine, Peking University

First Hospital, No.8 Xishiku street, Beijing 100034, China

Full list of author information is available at the end of the article
}

(c) The Author(s). 2020 Open Access This article is licensed under a Creative Commons Attribution 4.0 International License, which permits use, sharing, adaptation, distribution and reproduction in any medium or format, as long as you give appropriate credit to the original author(s) and the source, provide a link to the Creative Commons licence, and indicate if changes were made. The images or other third party material in this article are included in the article's Creative Commons licence, unless indicated otherwise in a credit line to the material. If material is not included in the article's Creative Commons licence and your intended use is not permitted by statutory regulation or exceeds the permitted use, you will need to obtain permission directly from the copyright holder. To view a copy of this licence, visit http://creativecommons.org/licenses/by/4.0/. The Creative Commons Public Domain Dedication waiver (http://creativecommons.org/publicdomain/zero/1.0/) applies to the data made available in this article, unless otherwise stated in a credit line to the data. 
(Continued from previous page)

Conclusions: For patients undergoing surgery for pheochromocytoma or paraganglioma, intraoperative hypotension is associated with increased postoperative complications; and the harmful effects are level- and duration-dependent. The effects of intraoperative hypertension need to be studied further.

Keywords: Pheochromocytoma-paraganglioma, Intraoperative hypotension, Postoperative complications

\section{Background}

Pheochromocytoma and paraganglioma are uncommon neuroendocrine diseases with a combined annual incidence rate from 0.29 to 0.46 per 100,000 person-years [1]. Surgical resection is the mainstay for the management of these tumors. Because of excessive intraoperative catecholamine release, especially during endotracheal intubation, creation of pneumoperitoneum, manipulation of tumor, and dividing adrenal vein [2-4], dramatic hemodynamic fluctuation occurs frequently, making the perioperative management a great challenge for the anesthesiologists and intensivists.

Much attention has been paid to the hemodynamic management of these patients during surgery [5-7]. However, the criteria of intraoperative hemodynamic instability vary widely, including absolute thresholds and/or relative changes of systolic blood pressure (SBP), mean arterial pressure (MAP) and even heart rate (HR), leading to reported rates range from 22.7 to $91.1 \%$ [8-10]. More importantly, most of these criteria were defined arbitrarily but not according to the risks of postoperative morbidity and mortality.

In previous studies of patients following non-cardiac surgery, intraoperative hypotension is found to be associated with increased risks of acute kidney injury (AKI) [11, 12], myocardial injury [12, 13], delirium [14], stroke [15], and even death $[16,17]$. On the other hand, intraoperative hypertension is also reported to be associated with adverse outcomes [18]; although there are evidences that the harmful effects of intraoperative hypertension might be less than those of intraoperative hypotension [19]. Extreme hyper- and hypotension are more likely to occur during surgery for pheochromocytoma or paraganglioma. We, therefore, hypothesized that intraoperative hyperand/or hypotension were associated with the development of postoperative complications.

In this study, we aimed to analyze the relationship between different thresholds and durations of intraoperative hyper-/hypotension and the risk of postoperative complications in patients undergoing surgery for pheochromocytoma or paraganglioma.

\section{Methods}

This was a retrospective single-center cohort study. The database used in the present study was established years ago after approval by the Clinical Research Ethics Committee of Peking University First Hospital, Beijing, China
(2016-1062) [10]. For the purpose of the present study, we updated the database after another ethical approval (2018-47). All data were retrospectively collected. Because of the retrospective nature and that all data of patients were collected from the medical records, the local Ethics Committee agreed to exempt the written informed consent. However, the privacy of all participants was strictly protected.

\section{Patients}

Potential participants were patients who underwent surgery for pheochromocytoma or paraganglioma, of which the diagnoses were confirmed by postoperative pathologic examination, from January 1, 2005 to December 31, 2017 in Peking University First Hospital. Patients who met any of the following criteria were excluded: (1) age less than 18 years; (2) surgery involving non-tumor organs; (3) incomplete data collected from the medical record system.

\section{Data collection}

Patients' data were collected from the electronic medical record system of the hospital. Baseline and preoperative data included demographic characteristics (age, gender, body mass index [BMI]), previous comorbidity, American Society of Anesthesiology (ASA) classification, preoperative hemoglobin, baseline serum catecholamine level, size and location of tumor, medical treatment, as well as blood pressure and heart rate before surgery.

Intraoperative data included period of surgery, type and duration of anesthesia, type and duration of surgery, estimated blood loss, minimal hemoglobin, blood transfusion, positive fluid balance, hemodynamic parameters, use of antihypertensive drugs, and use of vasopressors.

Postoperative data included use and duration of vasopressors, intensive care unit (ICU) admission, use and duration of mechanical ventilation, length of stay in ICU and hospital after surgery, occurrence of complications during hospital stay, and in-hospital mortality.

The primary endpoint was a composite of the occurrence of AKI or other complications during hospital stay after surgery. AKI and its stage were diagnosed according to the Kidney Disease Improving Global Outcomes (KDIGO) criteria using the maximal change in serum creatinine value compared with the preoperative baseline and urine output [20]. Other postoperative complications were 
defined as any deviation from the normal postoperative course which required pharmacological treatment or interventional procedures, i.e., grade II or higher on the Clavien-Dindo classification [21].

To ensure the accuracy of the outcome database, two investigators collected the information of postoperative outcomes separately and independently. They were blinded to intraoperative blood pressure management at the time of postoperative data collection. In case of any difference between the two investigators, final agreement was achieved by rechecking medical records and full discussion with a senior physician.

\section{Preoperative antihypertensive treatment}

For a patient with diagnosed or strongly suspected pheochromocytoma or paraganglioma, the attending physician/surgeon would initiate the $\alpha$-blocker therapy with a starting dose while decreasing or ceasing other antihypertensive drugs used before. The dose of $\alpha$-blockers was gradually adjusted to achieve a target blood pressure while avoiding orthostatic hypotension. During this process, a calcium channel blocker and/or a $\beta$-adrenergic receptor blocker might be added when considered necessary.

\section{Intraoperative blood pressure management}

In case of hypertension which commonly occurred during stimulation or tumor manipulation, anesthesia depth was firstly checked and deepened when necessary. When hypertension persisted, intravenous antihypertensives such as phentolamine, urapidil and/or nicardipine as well as a short-acting beta-blocker esmolol were administered. Intravenous antihypertensives were ceased shortly before ligation of tumor vessels. In case of hypotension which frequently occurred after tumor removal, intravascular volume was re-evaluated and fluid resuscitation was performed when considered necessary. When hypotension persisted, intravenous vasopressors such as phenylephrine, norepinephrine and/or epinephrine were administered to maintain adequate organ perfusion.

\section{Processing of intraoperative blood pressure data}

The data of blood pressure was captured every $10 \mathrm{~s}$ and stored by the electronic anesthesia information system in a real-time manner and were examined separately and independently by two investigators (NL and HK). During episodes when no blood pressure was recorded or when artifacts were marked by the anesthesiologists, the last blood pressure was used to replace the missing data.

For the purpose of analysis, absolute thresholds of SBP with different durations were used to define intraoperative hyper-/hypotension. We adopt this criterion because SBP is the primary target of intervention [22]. Specifically, SBPs of $\geq 160,180$ and $200 \mathrm{mmHg}$ were used as thresholds for intraoperative hypertension and those of $\leq 100,95,90,85$, and $80 \mathrm{mmHg}$ for intraoperative hypotension, with durations of $1,5,10,20,30,40$ and 50 min, respectively.

\section{Statistical analysis}

Patients' data were analyzed according to the development of postoperative complications or not. Numeric data with normal distribution were compared using independent samples $t$ rest; numeric data with nonnormal distribution or ranked data were compared using Mann-Whitney U test. Categorical data were compared using chi-square test or Fisher's exact test. Time-toevent data were analyzed by Kaplan-Meier estimator, with difference between groups compared by log- rank test. The association between different thresholds and durations of intraoperative SBP and the development of postoperative complications were analyzed using the Logistic regression models. Independent variables with $P$ values $<0.10$ in univariate analyses or were considered clinically important were included in the multivariate models to adjust for confounding factors. Two-sided $P$ values of $<0.05$ were considered as statistically significant. For multiple comparisons, the thresholds of $P$ values were adjusted with Bonferroni correction. Statistical analyses were performed with the SPSS statistical package version 25.0 (IBM SPSS Inc., Chicago, IL, USA).

\section{Results \\ Patients}

From January 1, 2005 to December 31, 2017, 367 patients underwent surgery for pheochromocytoma or paraganglioma; among these, 327 met the inclusion/exclusion criteria and were included in final analysis (Fig. 1).

Of the enrolled patients, 43 (13.1\%) developed AKI or other complications during hospital stay after surgery (Table 1). When compared with patients who did not develop postoperative complications, those who did had a higher male ratio, more comorbidity of diabetes mellitus and previous stroke, larger tumor diameters, and more paragangliomas; they received more calcium channel blockers and combined antihypertensive therapies, had higher preoperative BP and HR, and underwent more surgery between 2010 and 2013 (Table 2). During surgery, patients who developed postoperative complications underwent longer anesthesia/surgery and more open surgery, lost more blood, had lower hemoglobin level, received more blood transfusion, had more positive fluid balance, and were given more antihypertensives and vasopressors (Table 2).

During the postoperative period, patients who developed postoperative complications received more vasopressors, were admitted to the ICU more frequently, underwent more and longer mechanical ventilation, and stayed longer in the ICU and hospital after surgery. No patient died during hospital stay (Table 3). 
367 patients underwent surgery for pheochromocytoma or paraganglioma from Jan 1, 2005 to Dec 31, 2017

40 patients excluded

10 age $<18$ years

24 surgeries involved non-tumor organs

6 data loss

327 patients eligible

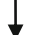

327 patients included in final analysis

Fig. 1 Flowchart of the study

\section{Intraoperative blood pressure}

The median percentage of no blood pressure record, calculated as the cumulated duration of no blood pressure record divided by the total duration of anesthesia, was $1.10 \%$ (interquartile range [IQR] 0.74 to $1.68 \%$ ). The median percentage of blood pressure with artifacts, calculated as the cumulated duration of blood pressure with artifacts divided by the total duration of anesthesia, was $0.27 \%$ (IQR 0.00 to $0.65 \%$ ). The durations of SBP below different thresholds were significantly longer after tumor removal than before (Fig. 2).

Table 1 Occurrence and severity of individual complications following surgery

\begin{tabular}{|c|c|c|c|c|c|c|c|}
\hline \multirow[t]{2}{*}{ Complications } & \multirow{2}{*}{$\begin{array}{l}\text { Total } \\
\text { number }\end{array}$} & \multicolumn{6}{|c|}{ Severity of postoperative complications ${ }^{a}$} \\
\hline & & $\|$ & Illa & IIIb & IVa & $\mathrm{IVb}$ & V \\
\hline Stroke $^{b}$ & 2 & 2 & - & - & - & - & - \\
\hline Respiratory complications & 6 & 4 & 2 & - & - & - & - \\
\hline Pulmonary infection ${ }^{c}$ & 4 & 4 & - & - & - & - & - \\
\hline Pleural effusion ${ }^{d}$ & 2 & - & 2 & - & - & - & - \\
\hline Cardiovascular complications & 3 & 2 & 1 & - & - & - & - \\
\hline New onset arrhythmia ${ }^{e}$ & 1 & - & 1 & - & - & - & - \\
\hline Acute myocardial infarction ${ }^{f}$ & 2 & 2 & - & - & - & - & - \\
\hline Surgery-related complications & 6 & 3 & - & 1 & 1 & 1 & - \\
\hline Surgical bleeding ${ }^{g}$ & 3 & - & - & 1 & 1 & 1 & - \\
\hline lleus $^{h}$ & 3 & 3 & - & - & - & - & - \\
\hline Thromboembolic complications & 3 & 2 & - & - & 1 & - & - \\
\hline Pulmonary embolism ${ }^{i}$ & 1 & - & - & - & 1 & - & - \\
\hline Deep venous thrombosis ${ }^{j}$ & 2 & 2 & - & - & - & - & - \\
\hline Hypoglycemia ${ }^{k}$ & 9 & 9 & - & - & - & - & - \\
\hline Urinary tract infection ' & 1 & 1 & - & - & - & - & - \\
\hline
\end{tabular}

Data are number

${ }^{a}$ According to Clavien-Dindo classification

${ }^{b}$ Persisted new focal neurologic deficit and confirmed by neurologic imaging

${ }^{c}$ Presence of at least one of the following manifestations, i.e., increased or color-changed sputum, new or changed pulmonary infiltrates, fever, and leukocyte

count $>12,000 / \mathrm{mm}^{3}$, and required antibiotic therapy

${ }^{d}$ Confirmed by chest X-ray or ultrasound examination and required drainage, aspiration, and/or diuresis after albumin administration

e New onset atrial fibrillation or paroxysmal supraventricular tachycardia that necessitated antiarrhythmic therapy

${ }^{f}$ Concentration of cardiac troponin I exceed the diagnostic criteria for myocardial infarction as well as new Q waves (lasts for $0.03 \mathrm{~s}$ ) or continuous (4 days)

abnormal ST-T segment

${ }^{g}$ Bleeding after surgery that required secondary surgical hemostasis

${ }^{h}$ Lack of bowel movement, flatulence, and requirement of parenteral nutrition for more than 1 week after surgery

${ }^{i}$ Confirmed by computed tomographic pulmonary angiography

${ }^{j}$ Confirmed by deep venous ultrasonography

${ }^{k}$ Defined as a documented serum blood glucose level of less than $55 \mathrm{mg} / \mathrm{dL}$

${ }^{\prime}$ Confirmed by urinalysis and urine culture and necessitated antibiotic therapy 
Table 2 Baseline and intraoperative variables

\begin{tabular}{|c|c|c|c|}
\hline Variables & Without postoperative complications $(n=284)$ & With postoperative complications ( $n=43$ ) & $P$ value $^{a}$ \\
\hline Age (years) & $46 \pm 15$ & $48 \pm 16$ & 0.379 \\
\hline Male gender ${ }^{b}$ & $119(41.9 \%)$ & $28(65.1 \%)$ & 0.004 \\
\hline $\mathrm{BMI}\left(\mathrm{kg} / \mathrm{m}^{2}\right)$ & $23.3 \pm 3.5$ & $23.2 \pm 3.7$ & 0.811 \\
\hline \multicolumn{4}{|l|}{ Preoperative comorbidity } \\
\hline Diabetes mellitus & $38(13.4 \%)$ & $12(27.9 \%)$ & 0.014 \\
\hline Coronary heart disease & $18(6.3 \%)$ & $1(2.3 \%)$ & 0.487 \\
\hline Previous stroke & $9(3.2 \%)$ & $7(16.3 \%)$ & 0.002 \\
\hline ASA classification ${ }^{b}$ & & & 0.223 \\
\hline 1 & $14(4.9 \%)$ & $2(4.7 \%)$ & \\
\hline 2 & $210(73.9 \%)$ & $26(60.5 \%)$ & \\
\hline 3 & $59(20.8 \%)$ & 15 (34.9\%) & \\
\hline 4 & $1(0.4 \%)$ & $0(0.0 \%)$ & \\
\hline \multicolumn{4}{|l|}{ Preoperative examination } \\
\hline Hemoglobin $(g / L)$ & $134 \pm 18$ & $133 \pm 24$ & 0.851 \\
\hline \multicolumn{4}{|l|}{ Serum catecholamine } \\
\hline Dopamine (pmol/L) & $0.10(0.05$ to 0.31$)$ & 0.10 (0.06 to 0.44$)$ & 0.412 \\
\hline Norepinephrine (pmol/L) & 11.7 (4.3 to 26.7$)$ & $15.3(4.9$ to 33.1$)$ & 0.397 \\
\hline Epinephrine (pmol/L) & 0.45 (0.09 to 0.90$)$ & $0.66(0.28$ to 1.20$)$ & 0.100 \\
\hline Maximal tumor diameter $(\mathrm{cm})^{b, c}$ & $5.3 \pm 2.2$ & $6.7 \pm 3.2$ & 0.012 \\
\hline Paraganglioma $^{b}$ & $53(18.7 \%)$ & $16(37.2 \%)$ & 0.005 \\
\hline \multicolumn{4}{|l|}{ Preoperative antihypertensives } \\
\hline a-AR antagonist ${ }^{d}$ & $246(86.6 \%)$ & $37(86.0 \%)$ & 0.918 \\
\hline Selective a1-AR antagonist & $144(58.5 \%)$ & $20(54.1 \%)$ & 0.607 \\
\hline$\beta-A R$ antagonist & $65(22.9 \%)$ & $12(27.9 \%)$ & 0.470 \\
\hline Calcium channel blocker & $73(25.7 \%)$ & $20(46.5 \%)$ & 0.005 \\
\hline Combined $^{b}$ & $83(29.2 \%)$ & $22(51.2 \%)$ & 0.004 \\
\hline Intravenous fluid & $140(49.6 \%)$ & $22(51.2 \%)$ & 0.853 \\
\hline Preoperative SBP (mmHg) & $125 \pm 17$ & $131 \pm 13$ & 0.040 \\
\hline Preoperative DBP (mmHg) & $77 \pm 12$ & $81 \pm 10$ & 0.025 \\
\hline Preoperative HR (bpm) & $74 \pm 11$ & $78 \pm 9$ & 0.020 \\
\hline Period of surgery ${ }^{b}$ & & & 0.005 \\
\hline $2005-2009$ & $65(22.9 \%)$ & $7(16.3 \%)$ & \\
\hline 2010-2013 & $61(21.5 \%)$ & $19(44.2 \%)$ & \\
\hline 2014-2017 & $158(55.6 \%)$ & $17(39.5 \%)$ & \\
\hline Duration of anesthesia (min) & $214 \pm 82$ & $308 \pm 148$ & $<0.001$ \\
\hline Type of anesthesia $^{b}$ & & & 0.055 \\
\hline General & $188(66.2 \%)$ & $22(51.2 \%)$ & \\
\hline Combined epidural-general $^{e}$ & $96(33.8 \%)$ & $21(48.8 \%)$ & \\
\hline Duration of surgery $(\min )^{b}$ & $129 \pm 75$ & $223 \pm 148$ & $<0.001$ \\
\hline Type of surgery ${ }^{b}$ & & & 0.015 \\
\hline Open & $89(31.3 \%)$ & $23(53.5 \%)$ & \\
\hline Laparoscopic & $192(67.6 \%)$ & $20(46.5 \%)$ & \\
\hline Transurethral & $3(1.1 \%)$ & $0(0.0 \%)$ & \\
\hline Estimated blood loss (ml) & 100 (50 to 300$)$ & 500 (100 to 1800$)$ & $<0.001$ \\
\hline
\end{tabular}


Table 2 Baseline and intraoperative variables (Continued)

\begin{tabular}{llll}
\hline Variables & Without postoperative complications $(n=284)$ & With postoperative complications $(n=43)$ & $P$ value ${ }^{a}$ \\
\hline Minimal hemoglobin $(\mathrm{g} / \mathrm{L})$ & $110 \pm 22$ & $96 \pm 22$ & $\mathbf{0 . 0 0 1}$ \\
Blood transfusion $^{b, f}$ & $37(13.0 \%)$ & $20(46.5 \%)$ & $\mathbf{<}$ \\
Positive fluid balance $(\mathrm{ml})^{\text {Use of antihypertensives }}$ & $2200(1500$ to 3025$)$ & $3150(2350$ to 5475$)$ & $\mathbf{0 . 0 0 1}$ \\
Combined antihypertensives $^{b, g}$ & $243(85.6 \%)$ & $41(95.3 \%)$ & $\mathbf{0 . 0 7 7}$ \\
Use of vasopressors $^{b}$ & $173(60.9 \%)$ & $34(79.1 \%)$ & $\mathbf{0 . 0 2 1}$ \\
Combined vasopressors $^{h}$ & $129(45.4 \%)$ & $16(37.2 \%)$ & $\mathbf{0 . 0 0 1}$ \\
\hline
\end{tabular}

Data are presented as mean $\pm \mathrm{SD}$, number (\%), or median (interquartile range)

$B M I$ Body mass index, ASA American Society of Anesthesiologists, AR Adrenergic receptor, SBP Systolic blood pressure, DBP Diastolic blood pressure, HR Heart rate

${ }^{a}$ Comparison between patients with or without postoperative complications

${ }^{b}$ Variables adjusted in the multivariate model

${ }^{c}$ Confirmed by postoperative pathologic examination results

${ }^{d}$ Including phenoxybenzamine, doxazosin and terazosin. Forty four patients did not receive a-AR antagonist therapy due to normal blood pressure and serum catecholamine level before surgery. Diagnosis of pheochromocytoma was confirmed by postoperative pathologic examination

${ }^{e}$ These patients also received postoperative patient-controlled epidural analgesia (PCEA)

${ }^{f}$ Includes packed red blood cell, fresh frozen plasma, and/or concentrated platelet

${ }^{g}$ Combined use of two or more intravenous antihypertensive drugs, including phentolamine, urapidil, nicardipine and/or esmolol

${ }^{h}$ Combined use of two or more intravenous vasopressors, including phenylephrine, norepinephrine, and/or epinephrine

\section{Identification of potential confounding factors}

Univariate analyses identified 24 variables with $P$ values $<0.10$ (Additional file 1: Supplementary Table 1). After testing for correlation, 12 variables were entered into the multivariate model to adjust for confounding factors, including male gender, ASA classification $(3+4$ vs. $1+2)$, maximal tumor diameter $(\mathrm{cm})$, paraganglioma, preoperative combined antihypertensives, period of surgery, type of anesthesia (combined epidural-general vs. general), duration of surgery (minute), type of surgery (open vs. laparoscopic/transurethral), intraoperative blood transfusion, combined antihypertensives during surgery and use of vasopressor during surgery (Table 4).

\section{Association between intraoperative hyper-/hypotension and postoperative complications}

Multivariate Logistic regression analyses showed that SBP of $\leq 95 \mathrm{mmHg}$ for $\geq 20 \mathrm{~min}$ (OR 3.211; 99\% CI 1.081-9.536; $P=0.006$ ), SBP of $\leq 90 \mathrm{mmHg}$ for $\geq 20 \mathrm{~min}$ (OR 3.680; 98.8\% CI 1.107-12.240; $P=0.006$ ), SBP of

Table 3 Postoperative outcomes

\begin{tabular}{|c|c|c|c|}
\hline Variables & Without postoperative complications $(n=284)$ & With postoperative complications $(n=43)$ & $P$ value \\
\hline Acute kidney injury $^{a}$ & - & $23(53.5 \%)$ & - \\
\hline Stage 1 & - & $19(44.2 \%)$ & - \\
\hline Stage 2 & - & $4(9.3 \%)$ & - \\
\hline Other postoperative complications & - & $30(69.8 \%)$ & - \\
\hline Use of vasopressors ${ }^{b}$ & $47(16.5 \%)$ & $19(44.2 \%)$ & $<0.001$ \\
\hline Duration of vasopressors $(\mathrm{hr})^{c}$ & $18.2(11.8,24.7)$ & $22.1(8.8,35.4)$ & 0.546 \\
\hline ICU admission & $174(61.3 \%)$ & $41(95.3 \%)$ & $<0.001$ \\
\hline Use of MV & $107(37.7 \%)$ & $33(76.7 \%)$ & $<0.001$ \\
\hline Duration of MV (hr) ${ }^{d}$ & $4.1(3.4,4.8)$ & $14.7(5.6,23.5)$ & 0.003 \\
\hline Length of ICU stay (day) ${ }^{e}$ & $1.4(1.2,1.5)$ & $2.2(1.8,2.7)$ & $<0.001$ \\
\hline Hospital stay after surgery (day) & $5.9(5.5,6.2)$ & $9.5(7.5,11.5)$ & $<0.001$ \\
\hline In-hospital mortality & $0(0.0 \%)$ & $0(0.0 \%)$ & - \\
\hline
\end{tabular}

Data were presented as number of patients (percentage) or mean ( $95 \%$ confidence interval)

ICU Intensive care unit, MV Mechanical ventilation

${ }^{a}$ Defined as increase in serum creatinine by $\geq 26.5 \mu \mathrm{mol} / \mathrm{l}$ within $48 \mathrm{~h}$; or increase in serum creatinine to $\geq 1.5$ times baseline, which is known or presumed to have occurred within the prior 7 days; or urine volume $<0.5 \mathrm{ml} / \mathrm{kg} / \mathrm{h}$ for $6 \mathrm{~h}$. Stage 1 was defined as serum creatinine 1.5-1.9 times baseline or $\geq 26.5 \mu \mathrm{mol} / \mathrm{l}$ increase or urine output $<0.5 \mathrm{ml} / \mathrm{kg} / \mathrm{h}$ for $6-12 \mathrm{~h}$; stage 2 was defined as serum creatinine $2.0-2.9$ times baseline or urine output $<0.5 \mathrm{ml} / \mathrm{kg} / \mathrm{h}$ for $\geq 12 \mathrm{~h}$; stage $3 \mathrm{was}$ defined as serum creatinine 3 times baseline or increase to $\geq 353.6 \mu \mathrm{mol} / \mathrm{l}$ or initiation of renal replacement therapy or urine output $<0.3 \mathrm{ml} / \mathrm{kg} / \mathrm{h} \geq 24 \mathrm{~h}$ or anuria $\geq 12 \mathrm{~h}$

${ }^{b}$ Requirement of vasopressors (norepinephrine or epinephrine) to maintain systolic blood pressure $\geq 90 \mathrm{mmHg}$ after surgery

${ }^{c}$ Results of patients who required vasopressors after surgery

${ }^{d}$ Results of patients who required mechanical ventilation in the ICU after surgery

${ }^{e}$ Results of patients who were admitted to the ICU after surgery 


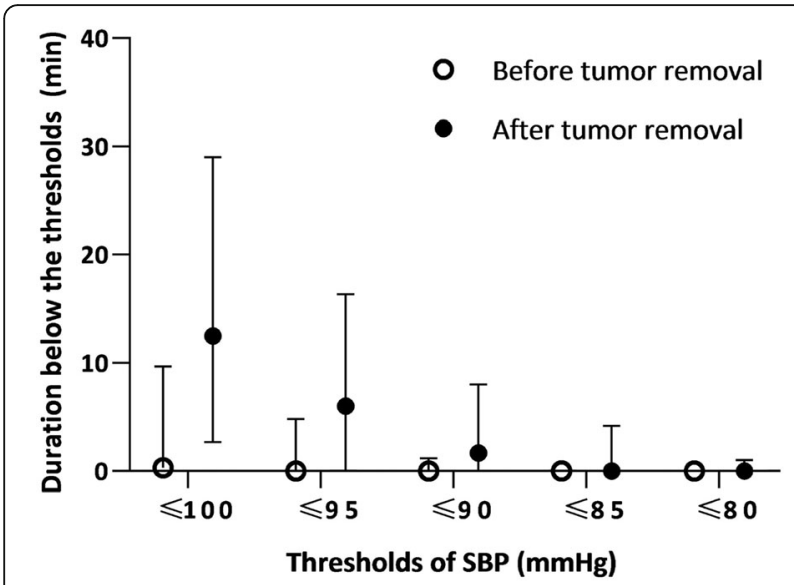

Fig. 2 The duration of SBP below different thresholds before and after tumor removal. The spots and whiskers plots show medians (interquartile range). $P<0.001$ for all thresholds of SBP. $P<0.01$ $(0.05 / 5)$ were considered statistically significant after Bonferroni correction. SBP, systolic blood pressure

$\leq 85 \mathrm{mmHg}$ for $\geq 10 \mathrm{~min}$ (OR 3.975; 98.3\% CI 1.32111.961; $P=0.003$ ), and SBP of $\leq 80 \mathrm{mmHg}$ for $\geq 1 \mathrm{~min}$ (OR 3.465; 95\% CI 1.484-8.093; $P=0.004$ ) were significantly associated with an increased risks of postoperative complications after Bonferroni correction. On the other hand, intraoperative hypertension, defined as SBP of different thresholds for different durations, was not significantly associated with the development of postoperative complications (Table 4).

\section{Discussion}

Results of this retrospective study showed that, in patients undergoing surgery for pheochromocytoma or paraganglioma, intraoperative hypotension was associated with an increased risk of postoperative complications; whereas intraoperative hypertension was not. The harmful effects of intraoperative hypotension seemed "dose-dependent", i.e., higher threshold with longer duration or lower threshold with shorter duration was associated with an increased risk of postoperative complications. Our results provided further evidence regarding the blood pressure management for these patients during surgery.

To avoid ambiguity, postoperative complications and their severities were clearly defined in the present study. In our patients, $13.1 \%$ developed postoperative complications; this was consistent with the multicenter study of Brunaud et al. [9] who reported an incidence of $16 \%$ after laparoscopic adrenalectomy for pheochromocytoma. Among all individual complications, AKI was the most common one and occurred in $7.0 \%$ of our patients, higher than the reported rate of $2.8 \%$ after surgery for nonfunctional adrenal tumors [23], possibly due to more severe/frequent intraoperative hypotension [12, 24]. Other individual complications included hypoglycemia (2.8\%), pulmonary infection (1.2\%), and so forth (Table 1 ).

Cumulative evidence showed an association between intraoperative hypotension and postoperative morbidity in patients undergoing abdominal [25, 26], vascular [27] and cardiac surgeries [28]. Intraoperative hypotension was found to be related to the development of myocardial injury [12, 13, 26, 27, 29], AKI [11, 12, 29, 30], and even death $[16,17,31]$ after surgery. However, evidence in patients undergoing surgery for pheochromocytoma or paraganglioma are limited. In line with the above results, our study found that intraoperative hypotension is an independent risk factor of postoperative complications. Gaujoux et al. [32] also reported that perioperative hemodynamic instability, defined as the need for a cumulative dose of norepinephrine of $>5 \mathrm{mg}$, is significantly associated with morbidity development after surgery for pheochromocytoma. Currently, there are no widely accepted definition of intraoperative hypotension. In a recent systematic review, elevated risks of endorgan injury were presented for prolonged exposure ( $\geq 10 \mathrm{~min}$ ) to $\mathrm{MAP}<80 \mathrm{mmHg}$, for shorter durations < $70 \mathrm{mmHg}$, and for any exposure $<55-50 \mathrm{mmHg}$ [33]. In accordance with this trend, our study revealed that the risk of postoperative complications increased when SBP $\leq 95 \mathrm{mmHg}$ for $\geq 20 \mathrm{~min}$, SBP $\leq 90 \mathrm{mmHg}$ for $\geq 20 \mathrm{~min}$, SBP $\leq 85 \mathrm{mmHg}$ for $\geq 10 \mathrm{~min}$, and SBP $\leq 80 \mathrm{mmHg}$ for $\geq 1$ min (Table 4). However, it should be noted that our results do not demonstrate a causal relationship due to the retrospective study design. Furthermore, the external validity of the above thresholds and durations should consider treatment factors, such as fluid infusion and use of vasopressors.

The possible mechanisms underlying the development of end organ injuries from intraoperative hypotension may include the following. First of all, hypotension contributed to the imbalance of oxygen delivery-consumption in vital organs by decreasing oxygen supply [34]; the resulting ischemia-reperfusion injury then triggered inflammation responses which might be involved in the damage process [12, 17, 35]. In addition, intraoperative hypotension might be a marker of other intraoperative events and comorbidities that were associated with an increased risk of postoperative complications [36]. At last, improper use of catecholamine infusion during hypotension might have adverse effects on splanchnic blood flow which led to potentially deleterious consequences [37, 38].

Interestingly, our study did not find any significant association between intraoperative hypertension and postoperative complications. Similar results were also reported by others. For example, in a retrospective cohort study, Monk et al. [19] found that intraoperative hypotension, but not hypertension, was associated with increased 30-day mortality after non-cardiac surgery. 
Table 4 Association between intraoperative hyper-/hypotension and postoperative complications

\begin{tabular}{|c|c|c|c|c|c|}
\hline \multirow{2}{*}{$\begin{array}{l}\text { Thresholds and } \\
\text { durations }\end{array}$} & \multirow[t]{2}{*}{ N } & \multicolumn{2}{|l|}{ Univariate analysis } & \multicolumn{2}{|l|}{ Multivariate analysis ${ }^{a}$} \\
\hline & & OR $(95 \% \mathrm{Cl})$ & $P$ value & OR (adjusted Cl) & $P$ value \\
\hline $\mathrm{SBP} \geq 200 \mathrm{mmHg}$ & & & & $(95 \% \mathrm{Cl}), P<0.05$ & \\
\hline$\geq 1 \mathrm{~min}$ & 97 & $1.485(0.760-2.902)$ & 0.247 & $1.094(0.497-2.407)$ & 0.824 \\
\hline $\mathrm{SBP} \geq 180 \mathrm{mmHg}$ & & & & $(98.3 \% \mathrm{Cl}), P<0.017(0.05 / 3)^{b}$ & \\
\hline$\geq 1 \mathrm{~min}$ & 186 & $1.185(0.616-2.281)$ & 0.611 & $0.735(0.275-1.966)$ & 0.455 \\
\hline$\geq 5 \min$ & 99 & $1.130(0.569-2.246)$ & 0.727 & $0.719(0.268-1.930)$ & 0.425 \\
\hline$\geq 10 \mathrm{~min}$ & 63 & $1.321(0.613-2.847)$ & 0.478 & $0.792(0.259-2.424)$ & 0.619 \\
\hline $\mathrm{SBP} \geq 160 \mathrm{mmHg}$ & & & & $(99 \% \mathrm{Cl}), P<0.01(0.05 / 5)^{b}$ & \\
\hline$\geq 1 \mathrm{~min}$ & 270 & $1.099(0.463-2.611)$ & 0.831 & $0.753(0.175-3.240)$ & 0.617 \\
\hline$\geq 5$ min & 213 & $1.655(0.801-3.423)$ & 0.174 & $0.963(0.308-3.016)$ & 0.933 \\
\hline$\geq 10 \min$ & 161 & $1.217(0.640-2.314)$ & 0.550 & $0.702(0.254-1.940)$ & 0.370 \\
\hline$\geq 20 \min$ & 92 & $2.043(1.055-3.958)$ & 0.034 & $1.142(0.406-3.213)$ & 0.740 \\
\hline$\geq 30 \min$ & 53 & $2.294(1.090-4.828)$ & 0.029 & $1.234(0.387-3.933)$ & 0.641 \\
\hline $\mathrm{SBP} \leq 100 \mathrm{mmHg}$ & & & & $(99.3 \% \mathrm{Cl}), P<0.007(0.05 / 7)^{b}$ & \\
\hline$\geq 1 \mathrm{~min}$ & 278 & $4.065(0.950-17.390)$ & 0.059 & $3.141(0.338-29.226)$ & 0.166 \\
\hline$\geq 5 \min$ & 243 & $2.335(0.948-5.749)$ & 0.065 & $1.710(0.416-7.037)$ & 0.306 \\
\hline$\geq 10 \min$ & 211 & $2.685(1.201-6.002)$ & 0.016 & $1.839(0.511-6.617)$ & 0.200 \\
\hline$\geq 20 \mathrm{~min}$ & 162 & $3.017(1.489-6.113)$ & 0.002 & $1.809(0.573-5.714)$ & 0.164 \\
\hline$\geq 30 \min$ & 121 & $3.043(1.547-5.882)$ & 0.001 & $1.871(0.603-5.801)$ & 0.136 \\
\hline$\geq 40 \min$ & 83 & $4.293(2.211-8.336)$ & $<0.001$ & $2.535(0.796-8.076)$ & 0.030 \\
\hline$\geq 50 \min$ & 58 & 4.392 (2.199-8.774) & $<0.001$ & $2.625(0.828-8.320)$ & 0.024 \\
\hline $\mathrm{SBP} \leq 95 \mathrm{mmHg}$ & & & & $(99 \% \mathrm{Cl}), P<0.01(0.05 / 5)^{b}$ & \\
\hline$\geq 1 \mathrm{~min}$ & 245 & $2.253(0.915-5.551)$ & 0.077 & $1.746(0.446-6.834)$ & 0.293 \\
\hline$\geq 5 \min$ & 217 & $2.452(1.096-5.487)$ & 0.029 & $1.807(0.528-6.180)$ & 0.215 \\
\hline$\geq 10 \min$ & 170 & $2.695(1.330-5.458)$ & 0.006 & $1.916(0.640-5.735)$ & 0.126 \\
\hline$\geq 20 \min$ & 106 & $3.900(2.008-7.547)$ & $<0.001$ & $3.211(1.081-9.536)$ & 0.006 \\
\hline$\geq 30 \mathrm{~min}$ & 63 & $4.874(2.465-9.634)$ & $<0.001$ & $3.173(1.012-9.950)$ & 0.009 \\
\hline $\mathrm{SBP} \leq 90 \mathrm{mmHg}$ & & & & $(98.8 \% \mathrm{Cl}), P<0.012(0.05 / 4)^{b}$ & \\
\hline$\geq 1 \mathrm{~min}$ & 207 & $2.424(1.120-5.248)$ & 0.025 & $1.653(0.510-5.358)$ & 0.283 \\
\hline$\geq 5 \min$ & 147 & $2.588(1.324-5.058)$ & 0.005 & $1.662(0.579-4.769)$ & 0.226 \\
\hline$\geq 10 \min$ & 101 & $3.396(1.762-6.546)$ & $<0.001$ & $2.160(0.757-6.159)$ & 0.065 \\
\hline$\geq 20 \mathrm{~min}$ & 53 & $5.122(2.540-10.332)$ & $<0.001$ & $3.680(1.107-12.240)$ & 0.006 \\
\hline $\mathrm{SBP} \leq 85 \mathrm{mmHg}$ & & & & $(98.3 \% \mathrm{Cl}), P<0.017(0.05 / 3)^{b}$ & \\
\hline$\geq 1 \mathrm{~min}$ & 153 & $3.021(1.512-6.033)$ & 0.002 & $1.855(0.647-5.317)$ & 0.161 \\
\hline$\geq 5 \min$ & 93 & $3.516(1.822-6.783)$ & $<0.001$ & $2.039(0.739-5.621)$ & 0.094 \\
\hline$\geq 10 \min$ & 60 & $4.692(2.361-9.325)$ & $<0.001$ & $3.975(1.321-11.961)$ & 0.003 \\
\hline $\mathrm{SBP} \leq 80 \mathrm{mmHg}$ & & & & $(95 \% \mathrm{Cl}), P<0.05$ & \\
\hline$\geq 1 \mathrm{~min}$ & 98 & $5.062(2.580-9.935)$ & $<0.001$ & 3.465 (1.484-8.093) & 0.004 \\
\hline
\end{tabular}

$N$ Number, SBP Systolic blood pressure, OR Odds ratio, $\mathrm{Cl}$ Confidence interval

${ }^{a}$ Independent factors with $P$ values $<0.10$ in univariate analyses or were considered clinically important were included in the multivariate logistic regression model. These included male gender, ASA classification $(3+4$ vs. $1+2)$, maximal tumor diameter $(\mathrm{cm})$, paraganglioma, preoperative combined antihypertensives, period of surgery, type of anesthesia (combined epidural-general vs. general), duration of surgery (min), type of surgery (open vs. laparoscopic/transurethral), intraoperative blood transfusion, combined antihypertensives during surgery and use of vasopressors during surgery. History of diabetes mellitus and previous stroke were excluded due to correlation with ASA classification; preoperative calcium channel blocker, SBP, DBP and HR were excluded due to correlation with preoperative combined antihypertensives; duration of anesthesia and intraoperative positive fluid balance were excluded due to correlation with duration of surgery; intraoperative minimal hemoglobin and estimated blood loss were excluded due to correlation with intraoperative blood transfusion; use of antihypertensives during surgery was excluded due to correlation with combined antihypertensives during surgery; use of combined vasopressors during surgery were excluded due to correlation with use of vasopressors during surgery

${ }^{b}$ The threshold level of significance was corrected using the Bonferroni method 
One possible explanation is that patients with intraoperative hypertension often had experienced (and, thus, adapted to) hypertension before surgery; these might have made them more tolerable to intraoperative hypertension, but more vulnerable to hypotension. However, due to the retrospective nature of our study and the limited number of patients, the potential harmful effects of intraoperative hypertension cannot be excluded. Further studies are required to clarify whether and to what extent intraoperative hypertension affects outcomes in patients undergoing surgery for pheochromocytoma or paraganglioma.

In addition to the retrospective nature, there were some other limitations in our study. Firstly, given the long duration of this study, many innovations or new treatments were introduced during the studied period and might confound the results. However, after adjusting for period of surgery in the multivariate Logistic model, intraoperative hypotension remained an independent risk factor of postoperative complications (Table 4). Secondly, pheochromocytoma or paraganglioma are relatively rare diseases. Although the sample size was large in this study when compared with others, it was not enough to do further sensitivity analysis; for example, the impacts of hypotension with separate thresholds (SBP 95-90, 90-85, and $85-80 \mathrm{mmHg}$ ) for different durations $(1-5,5-10$, and $10-20 \mathrm{~min})$ on postoperative complications. Finally, patients' data were collected until hospital discharge. In a prospective study, Woodfield et al. [39] found that about one-third of complications occurred between hospital discharge and 30 days after surgery. Our results might have underestimated the incidence of postoperative complications.

\section{Conclusions}

For patients undergoing surgery for pheochromocytoma or paraganglioma, intraoperative hypotension is associated with increased postoperative complications; and the harmful effects of intraoperative hypotension are leveland duration-dependent. The effects of intraoperative hypertension need to be studied further.

\section{Supplementary information}

Supplementary information accompanies this paper at https://doi.org/10. 1186/s12871-020-01066-y.

Additional file 1 Supplementary Table 1. Univariate association between baseline/intraoperative variables and postoperative complications.

\section{Abbreviations}

AKI: Acute kidney injury; AR: Adrenergic receptor; ASA: American Society of Anesthesiologists; BMI: Body mass index; Cl: Confidence interval;
DBP: Diastolic blood pressure; HR: Heart rate; ICU: Intensive care unit; IQR: Interquartile range; KDIGO: Kidney Disease Improving Global Outcomes; MAP: Mean arterial pressure; MV: Mechanical ventilation; OR: Odds ratio; PCEA: Patient-controlled epidural analgesia; SBP: Systolic blood pressure

\section{Acknowledgements}

The authors gratefully acknowledge Dr. Qi Tang (MD, Department of Urology, Peking University First Hospital, Beijing, China) for his help in data collection.

\section{Authors' contributions}

NL: study development, data collection, data editing; first draft manuscript; HK: study development, data collection, manuscript editing; SLL: study design; SNZ: statistical analysis; ZZ: study design; DXW: study design, final version of manuscript. The authors read and approved the final manuscript.

\section{Funding}

The study was funded by the National Key R\&D Program of China (2018YFC2001800). The study sponsor had no role in study design, data acquisition, analysis, interpretation of results, or in the writing of the report.

Availability of data and materials

The datasets used and/or analyzed during the current study are available from the corresponding author on reasonable request.

\section{Ethics approval and consent to participate}

The study protocol was approved by the Clinical Research Ethics Committee of Peking University First Hospital (No. 2016-1062 and 2018-47). The ethics committee agreed to exempt written informed consent.

Consent for publication

Not applicable.

\section{Competing interests}

The authors declare that they have no competing interests.

\section{Author details}

${ }^{1}$ Department of Anesthesiology and Critical Care Medicine, Peking University First Hospital, No.8 Xishiku street, Beijing 100034, China. ${ }^{2}$ Department of Biostatistics, Peking University First Hospital, Beijing, China. ${ }^{3}$ Department of Urology, Peking University First Hospital, Beijing, China.

Received: 21 February 2020 Accepted: 8 June 2020

Published online: 12 June 2020

References

1. Berends AMA, Buitenwerf E, de Krijger RR, Veeger NJGM, van der HorstSchrivers ANA, Links TP, et al. Incidence of pheochromocytoma and sympathetic paraganglioma in the Netherlands: a nationwide study and systematic review. Eur J Intern Med. 2018;51:68-73. https://doi.org/10.1016/j. ejim.2018.01.015.

2. Kierman CM, Du L, Chen X, Broome JT, Shi C, Peters MF, et al. Predictors of hemodynamic instability during surgery for pheochromocytoma. Ann Surg Oncol. 2014;21(12):3865-71. https://doi.org/10.1245/s10434-014-3847-7.

3. Siddiqi $H$, Yang $H$, Laird A, Fox AC, Doherty GM, Miller BS, et al. Utility of oral nicardipine and magnesium sulfate infusion during preparation and resection of pheochromocytomas. Surgery. 2012;152(6):1027-36. https://doi. org/10.1016/j.surg.2012.08.023.

4. Naranjo J, Dodd S, Martin YN. Perioperative management of pheochromocytoma. J Cardiothorac Vasc Anesth. 2017;31(4):1427-39. https://doi.org/10.1053/j.jvca.2017.02.023.

5. de Fourmestraux A, Salomon L, Abbou CC, Grise P. Ten year experience of retroperitoneal laparoscopic resection for pheochromocytomas: a dualCentre study of 72 cases. World J Urol. 2015;33(8):1103-7. https://doi.org/10. 1007/s00345-014-1397-z.

6. Livingstone M, Duttchen K, Thompson J, Sunderani Z, Hawboldt G, Sarah Rose $M$, et al. Hemodynamic stability during Pheochromocytoma resection: lessons learned over the last two decades. Ann Surg Oncol. 2015;22(13): 4175-80. https://doi.org/10.1245/s10434-015-4519-y. 
7. Agrawal R, Mishra SK, Bhatia E, Mishra A, Chand G, Agarwal G, et al. Prospective study to compare perioperative hemodynamic alterations following preparation for pheochromocytoma surgery by phenoxybenzamine or prazosin. World J Surg. 2014;38(3):716-23.

8. Chang RY, Lang BH, Wong KP, Lo CY. High pre-operative urinary norepinephrine is an independent determinant of peri-operative hemodynamic instability in unilateral pheochromocytoma/paraganglioma removal. World J Surg. 2014;38(9):2317-23. https:/doi.org/10.1007/s00268-014-2597-9.

9. Brunaud L, Nguyen-Thi PL, Mirallie E, Raffaelli M, Vriens M, Theveniaud PE, et al. Predictive factors for postoperative morbidity after laparoscopic adrenalectomy for pheochromocytoma: a multicenter retrospective analysis in 225 patients. Surg Endosc. 2016;30(3):1051-9. https://doi.org/10.1007/ s00464-015-4294-7.

10. Li N, Kong H, Li SL, Zhu SN, Wang DX. Combined epidural-general anesthesia was associated with lower risk of postoperative complications in patients undergoing open abdominal surgery for pheochromocytoma: a retrospective cohort study. PLoS One. 2018;13(2):e0192924. https://doi.org/ 10.1371/journal.pone.0192924.

11. Hallqvist L, Granath F, Huldt E, Bell M. Intraoperative hypotension is associated with acute kidney injury in noncardiac surgery: an observational study. Eur J Anaesthesiol. 2018;35(4):273-9. https://doi.org/10.1097/EJA. 0000000000000735.

12. Salmasi V, Maheshwari K, Yang D, Mascha EJ, Singh A, Sessler DI, et al. Relationship between intraoperative hypotension, defined by either reduction from baseline or absolute thresholds, and acute kidney and myocardial injury after noncardiac surgery: a retrospective cohort analysis. Anesthesiology. 2017;126(1):47-65.

13. Hallqvist L, Mårtensson J, Granath F, Sahlén A, Bell M. Intraoperative hypotension is associated with myocardial damage in noncardiac surgery: an observational study. Eur J Anaesthesiol. 2016;33(6):450-6. https://doi.org/ 10.1097/EJA.0000000000000429.

14. Radinovic K, Markovic Denic L, Milan Z, Cirkovic A, Baralic M, Bumbasirevic V. Impact of intraoperative blood pressure, blood pressure fluctuation, and pulse pressure on postoperative delirium in elderly patients with hip fracture: a prospective cohort study. Injury. 2019;50(9):1558-64. https://doi. org/10.1016/j.injury.2019.06.026

15. Sun LY, Chung AM, Farkouh ME, van Diepen S, Weinberger J, Bourke M, et al. Defining an intraoperative hypotension threshold in association with stroke in cardiac surgery. Anesthesiology. 2018;129(3):440-7. https://doi.org/ 10.1097/ALN.0000000000002298.

16. Mascha EJ, Yang D, Weiss S, Sessler DI. Intraoperative mean arterial pressure variability and 30-day mortality in patients having noncardiac surgery. Anesthesiology. 2015;123(1):79-91. https://doi.org/10.1097/ALN. 0000000000000686.

17. Bijker JB, van Klei WA, Vergouwe Y, Eleveld DJ, van Wolfswinkel L, Moons $K G$, et al. Intraoperative hypotension and 1-year mortality after noncardiac surgery. Anesthesiology. 2009;111:1217-26. https://doi.org/10.1097/ALN. Ob013e3181c14930.

18. Reich DL, Bennett-Guerrero E, Bodian CA, Hossain S, Winfree W, Krol M. Intraoperative tachycardia and hypertension are independently associated with adverse outcome in noncardiac surgery of long duration. Anesth Analg. 2002;95(2):273-7.

19. Monk TG, Bronsert MR, Henderson WG, Mangione MP, Sum-Ping ST, Bentt $\mathrm{DR}$, et al. Association between intraoperative hypotension and hypertension and 30-day postoperative mortality in noncardiac surgery. Anesthesiology. 2015;123(2):307-19. https://doi.org/10.1097/ALN.0000000000000756.

20. Kellum JA, Lameire N, Aspelin P, Barsoum RS, Mehta RL, Burdmann EA, et al. KDIGO clinical practice guideline for acute kidney injury 2012. Kidney Int. 2012;Suppl 2:1-138.

21. Katayama H, Kurokawa Y, Nakamura K, Ito H, Kanemitsu Y, Masuda N, et al. Extended Clavien-Dindo classification of surgical complications: Japan clinical oncology group postoperative complications criteria. Surg Today. 2016;46(6):668-85. https://doi.org/10.1007/s00595-015-1236-x.

22. Strandberg TE, Pitkala K. What is the most important component of blood pressure: systolic, diastolic or pulse pressure? Curr Opin Nephrol Hypertens. 2003;12(3):293-7.

23. Marcadis AR, Rubio GA, Khan ZF, Farra JC, Lew Jl. High perioperative morbidity and mortality in patients with malignant nonfunctional adrenal tumors. J Surg Res. 2017;219:259-65. https://doi.org/10.1016/j.jss.2017.05.116.

24. Tang Y, Zhu C, Liu J, Wang A, Duan K, Li B, et al. Association of Intraoperative Hypotension with acute kidney injury after noncardiac surgery in patients younger than 60 years old. Kidney Blood Press Res. 2019; 44(2):211-21. https://doi.org/10.1159/000498990.

25. Tassoudis V, Vretzakis G, Petsiti A, Stamatiou G, Bouzia K, Melekos M, et al. Impact of intraoperative hypotension on hospital stay in major abdominal surgery. J Anesth. 2011;25(4):492-9. https://doi.org/10.1007/s00540-0111152-1.

26. Kheterpal S, O'Reilly M, Englesbe MJ, Rosenberg AL, Shanks AM, Zhang L, et al. Preoperative and intraoperative predictors of cardiac adverse events after general, vascular, and urological surgery. Anesthesiology. 2009;110:5866. https://doi.org/10.1097/ALN.0b013e318190b6dc.

27. van Waes JA, van Klei WA, Wijeysundera DN, van Wolfswinkel L, Lindsay TF, Beattie WS. Association between intraoperative hypotension and myocardial injury after vascular surgery. Anesthesiology. 2016;124(1):35-44. https://doi. org/10.1097/ALN.0000000000000922.

28. Rettig TCD, Peelen LM, Geuzebroek GSC, van Klei WA, Boer C, van der Veer JW, et al. Impact of intraoperative hypotension during cardiopulmonary bypass on acute kidney injury after coronary artery bypass grafting. J Cardiothorac Vasc Anesth. 2017;31(2):522-8. https://doi.org/10.1053/j.jvca. 2016.07.040.

29. Walsh M, Devereaux PJ, Garg AX, Kurz A, Turan A, Rodseth RN, et al. Relationship between intraoperative mean arterial pressure and clinical outcomes after noncardiac surgery: toward an empirical definition of hypotension. Anesthesiology. 2013;119(3):507-15. https://doi.org/10.1097/ ALN.0b013e3182a10e26.

30. Sun LY, Wijeysundera DN, Tait GA, Beattie WS. Association of intraoperative hypotension with acute kidney injury after elective noncardiac surgery. Anesthesiology. 2015;123(3):515-23. https://doi.org/10.1097/ALN. 0000000000000765

31. Gu WJ, Hou BL, Kwong JSW, Tian X, Qian Y, Cui Y, et al. Association between intraoperative hypotension and 30-day mortality, major adverse cardiacevents, and acute kidney injury after non-cardiac surgery: a metaanalysis of cohort studies. Int J Cardiol. 2018;258:68-73. https://doi.org/10. 1016/j.ijcard.2018.01.137.

32. Gaujoux S, Bonnet S, Lentschener C, Thillois JM, Duboc D, Bertherat J, et al. Preoperative risk factors of hemodynamic instability during laparoscopic adrenalectomy for pheochromocytoma. Surg Endosc. 2016;30(7):2984-93. https://doi.org/10.1007/s00464-015-4587-x.

33. Wesselink EM, Kappen TH, Torn HM, Slooter AJC, van Klei WA. Intraoperative hypotension and the risk of postoperative adverse outcomes: a systematic review. Br J Anaesth. 2018;121(4):706-21. https://doi.org/10.1016/j.bja.2018. 04.036 .

34. Thygesen K, Alpert JS, Jaffe AS, Simoons ML, Chaitman BR, White HD, et al. Third universal definition of myocardial infarction. Eur Heart J. 2012;33:255167. https://doi.org/10.1093/eurheartj/ehs184.

35. Kalogeris T, Baines CP, Krenz M, Korthuis RJ. Ischemia/reperfusion. Compr Physiol. 2016;7(1):113-70. https://doi.org/10.1002/cphy.c160006.

36. Brady K, Hogue CW. Intraoperative hypotension and patient outcome: does "one size fit all?". Anesthesiology. 2013;119:495-7. https://doi.org/10.1097/ ALN.0b013e3182a10cce.

37. Wilkman E, Kaukonen KM, Pettilä V, Kuitunen A, Varpula M. Association between inotrope treatment and 90-day mortality in patients with septic shock. Acta Anaesthesiol Scand. 2013;57(4):431-42. https://doi.org/10.1111/ aas.12056.

38. Inoue T, Manley GT, Patel N, Whetstone WD. Medical and surgical management after spinal cord injury: vasopressor usage, early surgery and complications. J Neurotrauma. 2014;31(3):284-91. https://doi.org/10.1089/ neu.2013.3061.

39. Woodfield JC, Jamil W, Sagar PM. Incidence and significance of postoperative complications occurring between discharge and 30 days: a prospective cohort study. J Surg Res. 2016;206(1):77-82. https://doi.org/10. 1016/j.jss.2016.06.07.

\section{Publisher's Note}

Springer Nature remains neutral with regard to jurisdictional claims in published maps and institutional affiliations. 